\title{
Progressive Degradation and Subsequent Refinement of Acoustic Representations in the Adult Auditory Cortex
}

\author{
Shaowen Bao, Edward F. Chang, Jonathan D. Davis, Kevin T. Gobeske, and Michael M. Merzenich \\ Keck Center for Integrative Neuroscience, University of California, San Francisco, California 94143-0732
}

Correlated neuronal activity is believed to play an important role in refining and maintaining cortical circuitry during early development. Here we provide evidence that globally and locally correlated activity mediate different forms of adult plasticity. Pulses of broadspectrum noise were used to activate time-locked responses across large areas of the rat auditory cortex, globally synchronizing cortical activity. Brief tone pips were used to activate relatively small groups of neurons, generating locally correlated activity. Pairing pulsed noises with nucleus basalis (NB) stimulation in awake rats for 4 weeks broadened spectral tuning, disrupted tonotopic maps, and reduced spontaneous discharge correlation in the primary auditory cortex (AI), as examined under anesthesia. Those effects caused AI neurons to appear qualitatively similar to neurons in nonprimary auditory fields of naive animals. Subsequent pairing of tone pips with NB stimulation for a period of 4 weeks completely reversed these effects induced by previous noise-NB pairing. These findings further demonstrate that the adult auditory cortex retains a substantial capacity for receptive field plasticity and tonotopic map reorganization and that locally correlated activity plays an important role in plasticity in the adult, as in the developing cortex.

Key words: sensory; neuromodulator; acetylcholine; synchronization; forebrain; conditioning

\section{Introduction}

Although both the developing and the adult sensory cortices are capable of representational plasticity, they appear to be shaped by different types of experiences (Wiesel, 1982; Merzenich et al., 1990). In an early epoch of life known as the "critical period," passive sensory stimulation without explicit behavioral significance is sufficient to alter the organization of the sensory cortex (Wiesel and Hubel, 1965; Simons and Land, 1987; Sengpiel et al., 1999; Zhang et al., 2001). By contrast, passive experience has less influence on adult cortical sensory representations. The adult cortex appears to be reorganized more often through learning of behaviorally important sensory stimuli under attention-based and reinforced conditions (Diamond and Weinberger, 1986; Recanzone et al., 1992, 1993; Wang et al., 1995; Bakin et al., 1996; Plautz et al., 2000; Schoups et al., 2001).

Long-term potentiation can be induced in vitro when presynaptic activity precedes postsynaptic activity by up to $10-20 \mathrm{msec}$ (Markram et al., 1997; Zhang et al., 1998; Feldman, 2000; Froemke and Dan, 2002). In adult animals provided with sensory stimulation in vivo, however, similarly correlated presynaptic and postsynaptic activity are not sufficient to induce long-lasting cortical plasticity; an additional behavioral context is required (Ahissar et al., 1992). Recent studies suggest that neuromodulatory systems mediate these effects of behavioral context (Tremblay et al., 1990; Juliano et al., 1991; Webster et al., 1991a,b; Muir

\footnotetext{
Received 0ct. 17, 2002; revised Sept. 30, 2003; accepted Sept. 30, 2003

This research was supported by National Institutes of Health Grants NS-10414 and NS-34835, the Coleman Fund, the Mental Insight Foundation, and Hearing Research, Inc. We thank Drs. Eduardo Mercado III and Dan Polley for comments on this manuscript.

Correspondence should be addressed to Dr. Shaowen Bao, Keck Center for Integrative Neuroscience, University of California, San Francisco, CA 94143-0732. E-mail: bao@phy.ucsf.edu.

Copyright $\odot 2003$ Society for Neuroscience 0270-6474/03/2310765-11\$15.00/0
}

et al., 1993; Bakin and Weinberger, 1996; Dykes, 1997; Hollerman and Schultz, 1998; Kilgard and Merzenich, 1998a,b; Maalouf et al., 1998; Schultz and Dickinson, 2000; Shulz et al., 2000; Bao et al., 2001; Ji et al., 2001; Kilgard et al., 2001; Kisley and Gerstein, 2001; Mercado et al., 2001; Sarter et al., 2001; Ma and Suga, 2003). Brain cholinergic and dopaminergic systems are activated in the cortex during learning (Richardson and DeLong, 1990; Wilson and Rolls, 1990; Stark and Scheich, 1997). Systematically pairing microstimulation of cholinergic basal forebrain or dopaminergic ventral tegmentum neurons with sensory stimulation induces different types of cortical plasticity that resemble specific forms of plasticity induced by behavioral training (Bakin and Weinberger, 1996; Kilgard and Merzenich, 1998a; Bao et al., 2001; Kisley and Gerstein, 2001; Mercado et al., 2001).

In addition to activation of the neuromodulatory systems, neuronal activity is also required for cortical plasticity. Locally correlated activity, either stimulus-driven or spontaneous, is believed to play an important role in refining and maintaining the intricate cortical circuit during early development (Wiesel, 1982; Katz and Shatz, 1996; Sur and Leamey, 2001). Artificially increasing global neuronal discharge synchrony deprives the cortex of spatiotemporally or spectrotemporally patterned activity and disrupts functional development of the visual and auditory cortex (Cynader and Chernenko, 1976; Weliky and Katz, 1997; Zhang et al., 2002). The pattern of input activity also determines the forms of adult cortical plasticity (Kilgard et al., 2001). For example, synchronous stimulation of adjacent fingers resulted in abnormal multiple-digit receptive fields in the somatosensory cortex in the primate (Clark et al., 1988; Wang et al., 1995).

To understand how the pattern of input activity affects adult cortical plasticity, we paired pulsed noise and tone pips with nucleus basalis (NB) stimulation in adult animals. Pairing pulsed 
noise with basal forebrain stimulation rapidly and dramatically degraded functional organization of primary auditory cortex (AI). A degraded AI was subsequently restored in representational detail in all documented respects by pairing trains of tone pips with basal forebrain stimulation.

\section{Materials and Methods}

Preparation. Female Sprague Dawley rats (290-310 gm; 4-6 months old) were anesthetized with sodium pentobarbital. Platinum bipolarstimulating electrodes (SNE-200, Rhodes Medical Instruments, Woodland Hills, CA; $0.1 \mathrm{~mm}$ tip diameter and $0.5 \mathrm{~mm}$ separation) were stereotaxically implanted into the right nucleus basalis $(3.3 \mathrm{~mm}$ lateral and $2.3 \mathrm{~mm}$ posterior to bregma, $7.0 \mathrm{~mm}$ below the cortical surface). Three bone screws were threaded into a burr hole on the skull to anchor the electrode assembly. Leads were attached to the screws over the cerebellum and cortex to monitor cortical EEG during NB stimulation. All procedures were approved under University of California San Francisco Animal Care Facility protocols.

After a 2 week recovery period, rats were tested for the threshold of current microstimulation ( 20 biphasic pulses of $0.1 \mathrm{msec}$ duration at 100 $\mathrm{Hz}$ ) necessary to desynchronize cortical EEG during slow-wave sleep. A small four-pin connector attached to a swivel was used to record the EEG and deliver electric current pulses to the stimulating electrode. Rats with a desynchronization threshold at or below $200 \mu \mathrm{A}$ were included for further study.

A group of 14 awake and unrestrained rats received pairings of pulsed noise (six $25 \mathrm{msec}$ pulses; $5 \mathrm{msec}$ on/off ramps; delivered at a rate of 10 pulses per second; $65 \mathrm{~dB}$ total sound pressure level) with NB microstimulation (20 biphasic pulses of $0.1 \mathrm{msec}$ duration at $100 \mathrm{~Hz}$, initiated 200 msec after sound onset, typically $100-200 \mu \mathrm{A}$ ). The noise stimulus was generated using the LabView (National Instruments, Austin, TX) "uniform white noise" function and played through a National Instruments digital-to-analog converter at an update rate of $160 \mathrm{kHz}$. The white noise sequence was not "seeded" and therefore was unique for each trial. The spectrum of the noise stimuli has been reported previously (Zhang et al., 2002). Three hundred sixty pairing trials were delivered in daily $2 \mathrm{hr}$ sessions, with a random intertrial interval in the range of 12-28 sec. Pairing took place in a $25 \times 25 \times 25 \mathrm{~cm}$ wire cage located in a $50 \times 50 \times$ $50 \mathrm{~cm}$ sound-attenuation chamber lined with 3 inch acoustic foam. Overall sound attenuation was estimated at $40 \mathrm{~dB}$. The chamber was illuminated and well ventilated.

After $20 \mathrm{~d}$ ( $5 \mathrm{~d}$ /week, 4 weeks) of pulsed-noise pairing, experimental rats were arbitrarily assigned into one of four groups. The auditory cortex was mapped in six rats $24-48 \mathrm{hr}$ after the last pairing session. A second group of two rats were placed back in their home cages under standard housing conditions; their auditory cortices were mapped $30 \mathrm{~d}$ later. A third group of four rats received $20 \mathrm{~d}$ of pairing of a train of tone pips (six $25 \mathrm{msec}$ tone pips; $5 \mathrm{msec}$ on/off ramps, delivered at a rate of $10 \mathrm{pips} / \mathrm{sec}$; $65 \mathrm{~dB}$ sound pressure level (SPL)] with NB stimulation. A fourth group of two rats were given $20 \mathrm{~d}$ of exposure to trains of tone pips. The frequency of the tone pips that were presented to the third and fourth groups of rats was constant within a train but varied between trains. The tone frequency was randomly chosen for each tone train in the range of $1,000-20,000 \mathrm{~Hz}$. A group of four rats serving as auditory controls were exposed to pulsed noise $2 \mathrm{hr}$ daily for $20 \mathrm{~d}$. A separate control group of two rats received $20 \mathrm{~d}$ of $\mathrm{NB}$ stimulation alone.

Electrophysiological recording. Surgical anesthesia was induced with pentobarbital sodium $(50 \mathrm{mg} / \mathrm{kg})$. Throughout the surgical procedures and during the recording session, a state of areflexia was maintained with supplemental doses of dilute pentobarbital $(8 \mathrm{mg} / \mathrm{ml}$, i.p.). The trachea was cannulated to ensure adequate ventilation. The cisternae magnum was drained of cerebrospinal fluid to minimize cerebral edema. The skull was secured in a head holder leaving the ears unobstructed. After the right temporalis muscle was reflected, auditory cortex was exposed and the dura was resected. The cortex was maintained under a thin layer of viscous silicone oil to prevent desiccation. Recording sites were marked on an amplified digital image of the cortical surface vasculature.
Cortical responses were recorded with parylene-coated tungsten microelectrodes (1-2 M $\Omega$ at $1 \mathrm{kHz}$; FHC, Bowdoinham, ME). Recording sites were chosen to sample evenly from the auditory cortex while avoiding blood vessels. At every recording site the microelectrode was lowered orthogonally into the cortex to a depth of 470-550 $\mu \mathrm{m}$ (layers $4 / 5$ ), where vigorous stimulus-driven responses were obtained. The neural signal was amplified $(10,000 \times)$, filtered $(0.3-10 \mathrm{kHz})$, and monitored on-line. Acoustic stimuli were generated using TDT System II (TuckerDavis Technology, Alachna, FL) and delivered to the left ear through a calibrated earphone (STAX 54) positioned inside the pinnae. A software package (SigCal, SigGen, and Brainware; Tucker-Davis Technology) was used to calibrate the earphone, generate acoustic stimuli, monitor cortical response properties on-line, and store data for off-line analysis. The evoked spikes of a neuron or a small cluster of neurons were collected at each site. Single units were isolated either on-line using spike amplitude or off-line using principal components of the spike waveform.

Frequency-intensity receptive fields (RF) were reconstructed in detail by presenting pure tones of 60 frequencies $(1-30 \mathrm{kHz} ; 0.1$ octave increments; 25 msec duration; 5 msec ramps) at eight sound intensities (0-70 $\mathrm{dB}$ SPL in $10 \mathrm{~dB}$ increments) to the contralateral ear at a rate of two stimuli per second. The tones were presented in a random, interleaved sequence. In off-line RF analysis, activity after a tone was considered spontaneous and was removed from further analysis if all of the eight neighboring tones in the frequency-intensity stimulus grid (i.e., tones within \pm 0.1 octave of the frequency and within $\pm 10 \mathrm{~dB}$ of the intensity) failed to activate the neurons. A computer program was used to automatically characterize the tuning curve of each site as the cortical response threshold as a function of frequency. The characteristic frequency (CF) of a cortical site was defined as the frequency at the tip of the tuning curve. When a tuning curve had a broad tip or multiple peaks, the median frequency at the threshold intensity was chosen as the CF. Response bandwidth $30 \mathrm{~dB}$ above threshold (BW30) was defined as the bandwidth of the tuning curve $30 \mathrm{~dB}$ above the tip. For multipeaked tuning curves, the response bandwidth was defined as the range from the lowest to the highest frequency at $30 \mathrm{~dB}$ about the most sensitive tips that activated the cortical site, possibly encompassing the frequencies in a trough of the tuning curve that did not activate the cortical neurons. The CF and BW30 were automatically determined using computer programs. They were well correlated with those "blindly" characterized by an experienced observer $\left[r_{(201)}>0.95 ; p<0.0001\right.$ for both CF and BW30]. Two-dimensional autocorrelation series, $\operatorname{Corr}(\Delta f, \Delta I)$, of the binary (response-no response) RFs were also calculated. The central term $\operatorname{Corr}(0,0)$ was used as a measure of the size of the RFs. The periphery of the RF can be estimated using Corr $(0,0)-$ $(\operatorname{Corr}(1,0)+\operatorname{Corr}(0,1)) / 2$. For triangular-shaped RFs, the periphery is approximately proportional to the square root of the RF size. The ratio of RF periphery and square root of RF size would be higher for multipeaked or discontinuous RFs than for regular RFs. We defined RF irregularity index as $(\operatorname{Corr}(0,0)-(\operatorname{Corr}(1,0)+\operatorname{Corr}(0,1)) / 2] / \operatorname{Corr}(0,0)^{1 / 2}$ minus a constant number of 3 . The response latency was defined as the time from stimulus onset to the earliest response ( $4 \times \mathrm{SD}$ above baseline activity) for five frequencies that were nearest the $\mathrm{CF}$ at $70 \mathrm{~dB}$ SPL. Response magnitude was defined as the average number of spikes per tone, 7-50 msec after stimulus onset, for five frequencies nearest the CF at $70 \mathrm{~dB}$ SPL.

To generate cortical maps, Voronoi tessellation ("voronoi” is a Matlab function; The Mathworks, Inc.) was performed to create tessellated polygons, with the electrode penetration sites at their centers. Each polygon was assigned the characteristics (e.g., CF) of the corresponding penetration site. In this way, every point on the surface of the auditory cortex could be linked to the characteristics experimentally derived from a sampled cortical site that was closest to this point. The boundaries of the primary auditory cortex were functionally determined using the following criteria: (1) primary auditory neurons generally have a continuous, single-peaked, V-shaped receptive field, and (2) CFs of the AI neurons are tonotopically organized with high frequencies represented rostrally and low frequencies represented caudally.

To analyze neuronal discharge correlation, spontaneous or stimulusevoked activity was recorded simultaneously from three to four sites. For each pair-wise combination of the recording sites, a cross-correlogram (a histogram of between-site spike intervals) was constructed for a time 
window from -100 to $100 \mathrm{msec}$. An interval $<10 \mathrm{msec}$ (i.e., a pair of spikes within $10 \mathrm{msec}$ apart) was considered a synchronized event. The 10 msec time window was chosen because correlated presynaptic and postsynaptic spikes within this time window induce robust Hebbian plasticity (Markram et al., 1997; Zhang et al., 1998). The degree of synchronization was assessed using the total number and the percentage of synchronized events. The degree of synchronization resulting from transient responses to dynamic input was estimated for each pair of spike trains using a "shift predictor," which is defined as the cross-correlogram constructed after one of the spike trains was temporally shifted one trial forward relative to the other spike train, with the first trial of the spike train placed at its end (Perkel et al., 1967).

The degree of synchronization may be correlated with spike rates in a nonlinear manner. For each pair of spike trains, we estimated the number of synchronized events if the two spikes trains were not correlated, using $N_{A} N_{B} \Delta / T$, where $N_{A}$ and $N_{B}$ are the numbers of spikes in the two spike trains, $\Delta(=21 \mathrm{msec})$ is the bin size, and $T$ is the duration of recording (Eggermont, 1992). The strength of synchrony was then assessed using a $Z$-score of the number of synchronous events: $Z=$ (number of sync events $\left.-N_{A} N_{B} \Delta / T\right) /\left(N_{A} N_{B} \Delta / T\right)^{1 / 2}$ (Eggermont, 1992).

$\mathrm{RF}$ overlap between a pair of recorded sites was quantified with the ratio of the number of tone pips used for RF measurement that activated both sites and the number of tone pips that activated either site. All statistical analyses were done using StatView (SAS Institute Inc.) and the statistics toolbox of Matlab. Unless specified otherwise, statistical significance was assessed using unpaired two-tailed $t$ tests. Data are presented as mean \pm SEM.

\section{Results}

Increase in discharge synchrony by pulsed noise and tone stimuli

Previous studies indicate that synchronized neuronal activity may be mediated by transient input (Eggermont, 1994). Pulsed broadband noise should activate a large area of the auditory cortex and induce stimulus-locked synchronous neuronal discharge. In contrast, tone pips should activate a smaller group of neurons that are selective for the tone and synchronize activity among this more spatially limited group of neurons. We examined synchrony in cortical activity recorded from 22 pairs of sites in AI of a naive rat. Spikes trains were recorded during $3 \mathrm{sec}$ periods of silence, pulsed noise ( 10 pulses per second), and pulsed tones ( 25 msec pulses; $5 \mathrm{msec}$ on/off ramps, delivered at a rate of 10 pulses per second; $65 \mathrm{~dB}$ SPL; frequency at the CF of at least one of the two sites, similar to those used in stimulus-NB pairing). Figure $1 A$ shows the cross-correlograms of spike trains recorded from two sites that were $1 \mathrm{~mm}$ apart. The two sites had nonoverlapping RFs with CFs at 3 and $14 \mathrm{kHz}$. Spontaneous activity at the two sites was not correlated $\left(\chi_{(100)}^{2}=19.56 ; p>0.9\right)$. Pulsed noise, but not pulsed 3 or $14 \mathrm{kHz}$ tones, induced synchronized discharge [noise: $\chi_{(100)}^{2}=496.20, p<0.0001 ; 14-\mathrm{kHz}$ tone: $\left.\chi_{(100)}^{2}=39.29, p>0.9\right]$. In Figure $1 B$, the numbers of synchronized events (spike pairs within a $10 \mathrm{msec}$ interval) from all 22 recording pairs were summarized as a function of distance. For pairs of sites with distance $<1 \mathrm{~mm}$, both pulsed noises and pulsed tones increased the total number of synchronized events [paired $t$ test; noise vs spontaneous, $t_{(16)}=5.13, p<0.0005$; tone vs spontaneous, $t_{(16)}=2.86, p<0.05 ; p$ values of all paired $t$ tests were adjusted according to sequential Bonferroni's procedure to account for increased probability of a type I error (Quinn and Keough, 2002)], although pulsed noises had a stronger effect than pulsed tone $\left(t_{(16)}=4.66 ; p<0.001\right)$. For sites $>1 \mathrm{~mm}$ apart, pulsed noises increased total number of synchronous spikes, whereas pulsed tones reduced it (paired $t$ test; noise vs spontaneous, $t_{(4)}=2.93, p<0.05$; tone vs spontaneous, $t_{(4)}=4.14, p<$ $0.05)$. We also analyzed the percentage of synchronized events.
Pulsed noises increased the percentage of synchronized events regardless of the distance (paired $t$ test; $t_{(16)}=10.43, p<0.0005$ with distances $<1 \mathrm{~mm}$; $t_{(4)}=3.65, p<0.05$ with distances $>1$ $\mathrm{mm}$ ), whereas pulsed tones increased it for sites $<1 \mathrm{~mm}$ apart $\left(t_{(16)}=5.48 ; p<0.0005\right)$ but not for sites $>1 \mathrm{~mm}$ apart $\left(t_{(4)}=\right.$ $1.48 ; p>0.2)$. These results indicate that pulsed noises cause global synchronization, whereas pulsed tones induce local synchronization and long-distance desynchronization (i.e., reduced total numbers of synchronized spikes).

The chance level synchrony was estimated using $N_{A} N_{B} \Delta / T$, where $N_{A}$ and $N_{B}$ are the numbers of spikes in the two spike trains, $\Delta$ is the bin size, and $T$ is the duration of recording. The strength of discharge synchrony, estimated with a $Z$-score (Fig. 1D) (for details, see Materials and Methods), confirmed that pulsed noises increased discharge synchronization across all distances (paired $t$ test: $t_{(16)}=9.69, p<0.001$ with distances $<1$ $\mathrm{mm} ; t_{(4)}=5.22, p<0.05$ with distance $>1 \mathrm{~mm}$ ) and pulsed tones increased synchrony over short distances $\left(t_{(16)}=3.40 ; p<0.005\right)$ but not over long distances.

The number of events in the center $( \pm 10 \mathrm{msec})$ of a "shift predictor" was used to estimate the contributions of stimuluslocked transient responses to synchrony (for details, see Materials and Methods). There were fewer synchronized events for the shifted spontaneous spike trains than for the shifted pulsednoise- or pulsed-tone-activated spike trains (data not shown). When stimulus-locked synchronous events were removed by subtracting the shift predictor from the correlogram, spontaneous, tone-evoked, and noise-evoked spike trains showed a similar degree of synchrony for pairs of neurons that were $<1 \mathrm{~mm}$ apart (paired $t$ test; $\left.t_{(16)}=2.01 ; p>0.05\right)$ (Fig. $1 E$ ). For pairs of neurons that were $>1 \mathrm{~mm}$ apart, the shift-predictor-corrected synchrony was highest for spontaneous activity $\left(t_{(4)}=2.80 ; p<\right.$ $0.05)$ and lowest for noise-evoked responses $\left(t_{(4)}=3.82 ; p<\right.$ $0.05)$. These results suggest that the sound-induced increase in synchrony was caused by stimulus-locked responses.

To determine whether NB stimulation alters the patterns of tone- or noise-induced synchrony, we stimulated NB during acute recording (20 biphasic pulses of $0.1 \mathrm{msec}$ duration at 100 $\mathrm{Hz}$, once every $3 \mathrm{sec}$; typically $100-200 \mu \mathrm{A})$. Effective NB stimulation was confirmed visually by its facilitatory effects on spontaneous and tone-evoked discharge (Metherate et al., 1988; Metherate and Weinberger, 1990; Metherate and Ashe, 1993). Immediately after NB stimulation, pulsed tones or pulsed noise (same as those described before) were delivered. Spontaneous, tone-evoked, and noise-evoked spike trains in a $600 \mathrm{msec}$ window immediately after NB stimulation were recorded and analyzed in 30 pairs of neurons. NB stimulation did not significantly change the patterns of spontaneous and sound-induced synchrony: pulsed noises increased synchrony across all distances (paired $t$ test; $t_{(26)}=7.16, p<0.0005$ with distance $<1 \mathrm{~mm} ; t_{(5)}=5.05$, $p<0.05$ with distance $>1 \mathrm{~mm})$, and pulsed tones increased synchrony over short distances $\left(t_{(26)}=2.46 ; p<0.05\right)$ but not over long distances $\left(t_{(5)}=0.53 ; p>0.5\right)$ (Fig. $\left.1 F, G\right)$.

\section{Degradation and refinement of the primary auditory cortex by noise-NB and tone-NB pairing}

In naive adult rats, the auditory cortex consists of a well defined AI (Fig. 2A) and less well organized nonprimary auditory fields (see Fig. 6A). The AI and the nonprimary auditory areas can be distinguished by their receptive field properties: RFs of AI neurons are typically continuous, single-peaked, and V-shaped (Fig. $2 D)$; RFs of nonprimary auditory neurons are usually discontinuous, multipeaked, or broadly tuned. 


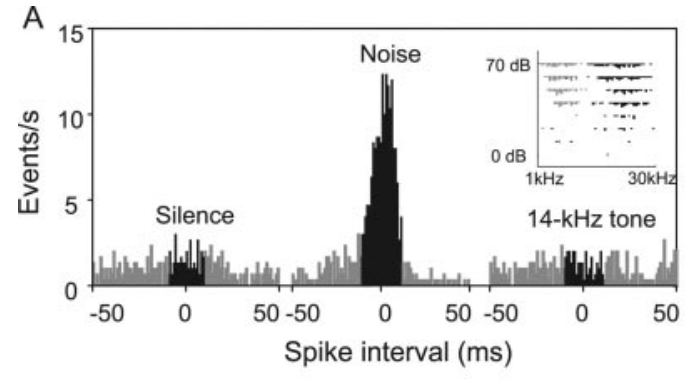

B-C. Synchronization-distance function

B

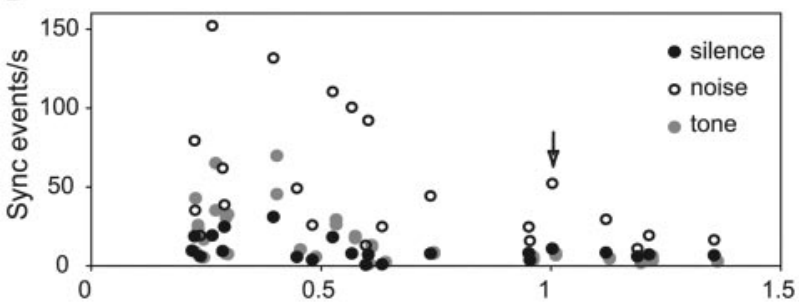

C

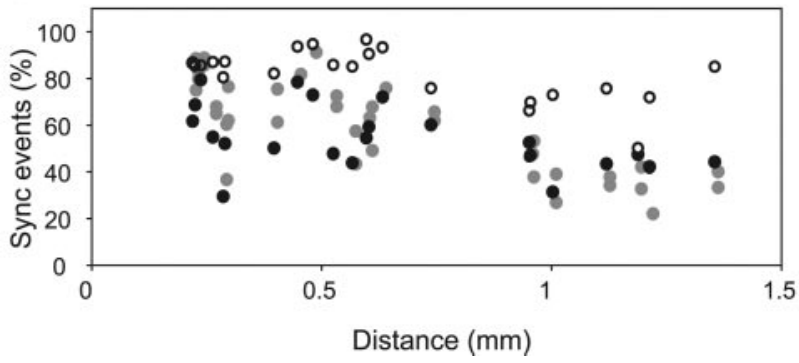

D

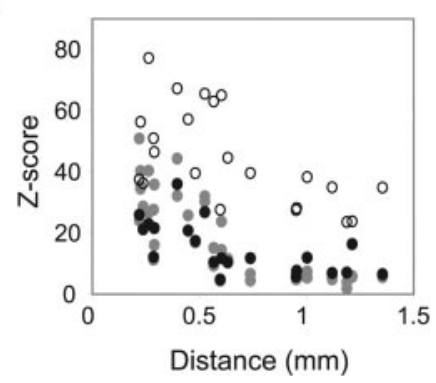

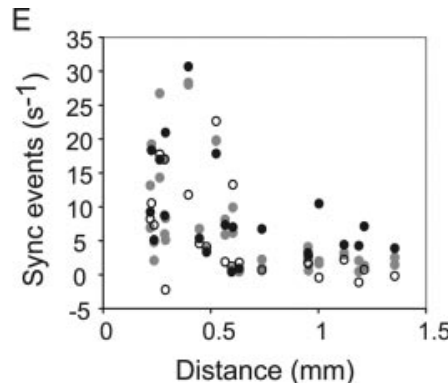

F-G. Synchronization-distance function with NB stimulation $\mathrm{F}$

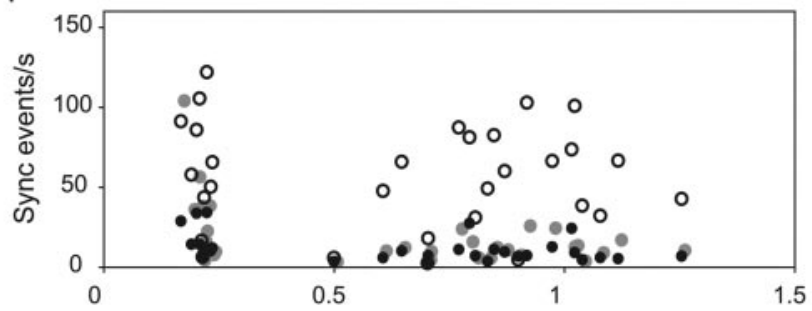

G

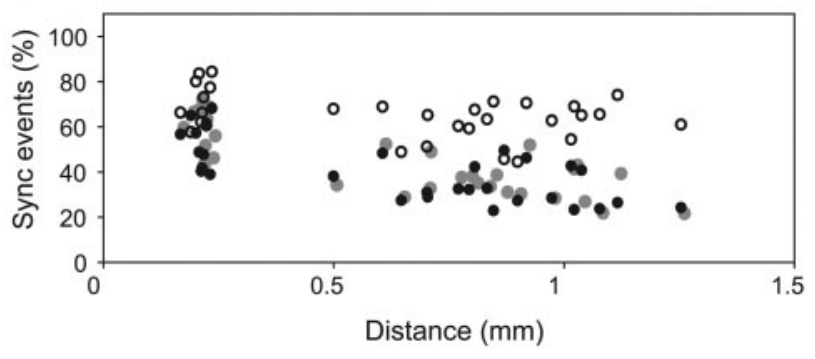

Figure 1. Pulsed noise evokes synchronized cortical activity. $A$, Cross-correlogram ( -50 to $50 \mathrm{msec}$ ) constructed using spikes recorded during 3 sec periods of silence, pulsed noise, and pulsed tone. The frequency of the tone was at the $C F$ of one of the neurons. The inset shows the frequency-intensity receptive fields of neurons sampled at the two sites. Noise but not tone synchronized activity of the two neurons. $B$, Total number of synchronized events as a function of distance. Spikes within $10 \mathrm{msec}$ apart are consider as synchronized. Cross-correlograms from the pair of sites marked with the arrow are presented in A. C, Percentage of the synchronized events as functions of cortical distance. D, Z-score of neuronal discharge synchrony (see Materials and Methods) as a function of distance. In $B-D$, pulsed noise increased neuronal synchrony across all distances (i.e., open circles tend to be above closed circles). Pulsed tones increased synchrony when distances were short and decreased synchrony when distances were long (i.e., red circles tend to be above closed circles with distances $<1 \mathrm{~mm}$, and below closed circles with distances $>1 \mathrm{~mm}$ ). E, Shift-predictorcorrected number of synchronous events (i.e., the total number of synchronous events minus the number of synchronous events after one of the two spike trains was temporally shifted relative to the other), which is the number of synchronous events that were not accounted for by stimulus-locked responses. Shift-predictor-corrected synchrony was not enhanced by tone or noise stimulation, suggesting that the tone- or noise-evoked synchrony was caused by stimulus-locked responses. $F, G$, Number and percentage of synchronous events in a 600 msec window after NB stimulation. Similar to results in $B$ and $C$, pulsed noise increased cortical synchrony across all distances, whereas tone pips increase synchrony only for sites $<1 \mathrm{~mm}$ apart.

Using RF characteristics to define AI became difficult in the noise-NB paired rats because the RFs of the AI neurons were mostly degraded. Discontinuous, multipeaked, and broadly tuned RFs were observed throughout the auditory cortex (Fig. $2 B, E, F)$. In noise-NB paired animals, the AI area therefore was determined primarily on the basis of its characteristic caudalrostral tonotopic axis. Although there are multiple auditory fields in the rat temporal cortex, low-frequency $(\leq 4 \mathrm{kHz})$ representations are located mainly in the caudal end of AI and nearby area (Figs. 2A-C, 6A,B). Using low-frequency selective sites as a landmark, AI can be reliably determined as the tonotopic field anterior and slightly dorsal to the low-frequency area. The border of the high-frequency (i.e., the anterior) end of AI was determined using sites that were not tuned to high frequencies $(>25 \mathrm{kHz})$. Other auditory fields are generally ventral to the low-frequency area (Figs. $2 A-C, 6 A, B$ ). To avoid bias, a computer program was used to determine the CFs on the basis of the recorded RFs. This was particularly important for the noise-NB paired animals because CFs for their AI neurons were often not obvious. Deter- mined in this way, the sizes of AI were not significantly different among the naive, noise-NB, and tone-NB groups $(1.11 \pm 0.14$ $\mathrm{mm}^{2}, n=4$, for the naive group; $1.14 \pm 0.20 \mathrm{~mm}^{2}, n=6$, for the noise-NB group; $1.12 \pm 0.20 \mathrm{~mm}^{2}, n=4$, for the tone-NB group; ANOVA: $\left.F_{(2,11)}=0.34 ; p>0.5\right)$. Furthermore, basic response properties such as response magnitude and latency were not different for primary auditory cortical neurons among the three groups [latency: $10.54 \pm 0.29 \mathrm{msec}(n=114)$ for naive group, $11.17 \pm 0.32 \mathrm{msec}$ for noise-NB group $(n=153), 10.77 \pm 0.26 \mathrm{msec}$ $(n=105)$ for tone-NB group, Kruskal-Wallis test, $p>0.1$; magnitude: $2.01 \pm 0.13$ spikes per tone for naive, $2.03 \pm 0.08$ for noise-NB, $2.17 \pm 0.10$ for tone-NB, Kruskal-Wallis test, $p>0.5$ ).

\section{Receptive field plasticity}

First, the sizes of receptive fields (i.e., the number of non-zero pixels in the frequency-intensity response window, excluding spontaneous activity; see Materials and Methods) of all AI sites were measured. Receptive fields were larger in noise-NB paired rats than in naive rats (noise-NB, $175.8 \pm 3.9$ pixels; naive, 

Naive B Noise-NB Noise-NB -> Tones-NB
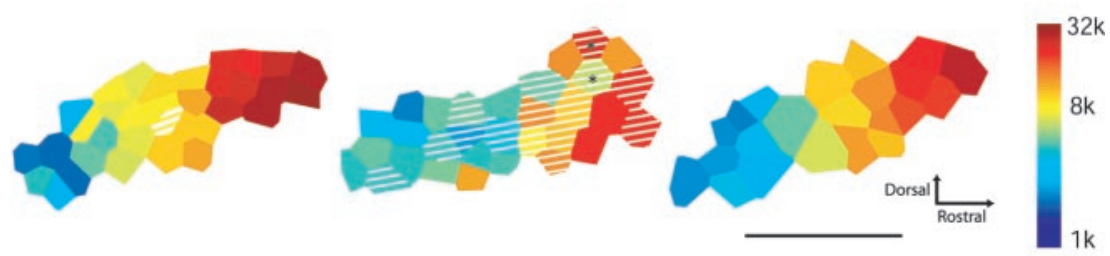

D

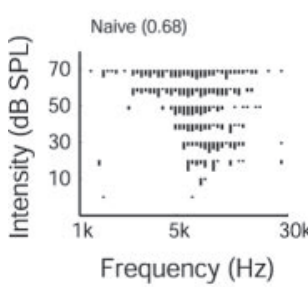

E Noise-NB (1.23)

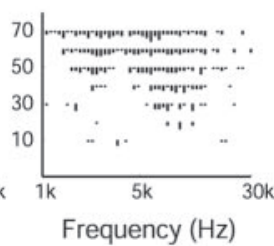

F

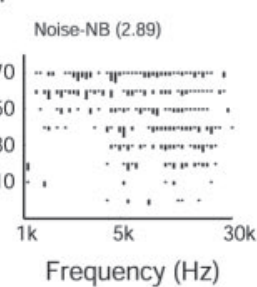

G

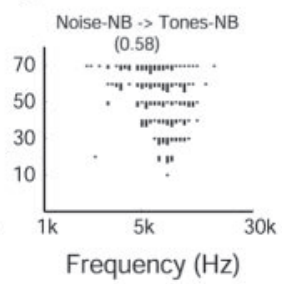

0.001). Furthermore, these measures were not significantly different from those recorded in the two rats that were exposed to trains of tone pips for $20 \mathrm{~d}$ after $20 \mathrm{~d}$ of noise-NB pairing ( $p>0.5$ for both BW30 and irregularity index). These results indicate that the refinement of noise-NBdegraded AI observed in the tone-NB rats (Figs. 2-4) was not caused by spontaneous recovery or exposure to tones.

\section{Cortical map disorganization and reorganization}

In addition to degrading AI RFs, noise-NB pairing also disorganized cortical maps (Fig. $2 B$ ). In noise-NB rats, there were often disproportionally large cortical areas representing narrow frequency bands. The overrepresented frequency bands varied among individual animals (Fig. $2 \mathrm{~B}, 5 \mathrm{kHz}$ in the AI; Fig. $6 \mathrm{~B}, 9 \mathrm{kHz}$ in the AI) and were not caused by uneven spectrum of the pulsed noise (Zhang et al., 2002). In contrast, nearby neurons were sometimes

$115.0 \pm 3.9$ pixels). Rats that received noise-NB pairing followed by tone-NB pairing did not have larger RFs (112.4 \pm 4.1 pixels; Kruskal-Wallis test, $p<0.005$; post hoc Bonferroni's comparison, noise-NB vs naive, $p<0.0001$; tone-NB vs naive, $p>0.5$ ).

The degraded spectral selectivity of the AI neurons in the noise-NB paired rats was quantified using BW30. The average BW30 measured in AI neurons of noise-NB paired animal was significantly greater than that observed in naive rats $(2.98 \pm 0.10$ octaves vs $2.32 \pm 0.11$ octaves) (Fig. $3 A$ ). The BW30 recorded in AI neurons of the tone-NB paired rats was similar to that of naive rats $(2.34 \pm 0.10$ octaves; Kruskal-Wallis test on all groups, $p<$ 0.0001; post hoc Bonferroni's comparison, noise-NB vs naive, $p<$ 0.0001 ; tone-NB vs naïve, $p>0.5$ ).

Many of the multipeaked and discontinuous RFs emerged in $\mathrm{AI}$ of the noise-NB paired animals (Fig. $2 B, E, F$ ). These changes were quantified using an RF irregularity index (Fig. 3B) (see Materials and Methods for calculation). Noise-NB pairing resulted in significantly higher RF irregularity compared with that of the naive group (Kruskal-Wallis test on all groups, $p<0.0001$; post hoc Bonferroni's comparison, $p<0.0001$ ). Subsequent tone-NB pairing reduced RF irregularity to a level lower than that of the naive group ( post hoc Bonferroni's comparison, $p<0.0001$ ). The sites with irregularity index $>2$ were rare in naive $\mathrm{AI}$, frequent in AI of noise-NB animals, and never seen in AI of tone-NB animals (Fig. 2A-C, hatched areas).

Neither exposure to the pulsed noise nor stimulation of nucleus basalis alone significantly altered the response bandwidths at $30 \mathrm{~dB}$ above threshold or the RF irregularity index (post hoc Bonferroni's comparison with the naive group: $\mathrm{BW} 30, p>0.5$; irregularity index, $p>0.5$ ) (Fig. 3), which confirms previous findings that acoustic exposure or NB stimulation alone causes little long-term reorganization in adult primary auditory cortex (Kilgard and Merzenich, 1998a; Zhang et al., 2001).

In the two rats that received $20 \mathrm{~d}$ of noise-NB pairing and were left alone for $30 \mathrm{~d}$ after the last pairing session, significant RF degradation was observed in AI neurons ( post hoc Bonferroni's comparison with the naive group: BW30, $p<0.001$; irregularity index, $p<0.05$ ) (Fig. 3), although some recovery in irregularity index may have occurred (comparing with noise-NB group, $p<$ tuned to distant frequencies in the noise-NB paired animals. In Figure $2 B$, for example, the two nearby sites in rostral AI marked with asterisks were tuned to 6.9 and $22.6 \mathrm{kHz}$ tones.

In naive animals, CFs increased gradually from caudal to rostral sites (Fig. 4A). In noise-NB-paired animals, this tonotopic order became less precise; all noise-NB-paired animals showed more scattered CF distributions along the rostrocaudal direction [Levene's equality of variances test (Levene, 1960) on residual variance after linear regression on all three groups; $F_{(2,369)}=$ 15.162, $p<0.0001$; post hoc Bonferroni's comparison, $p<$ $0.0001)$. Subsequent tone-NB pairing restored tonotopic organization of the cortical maps $(p>0.5)$.

Tonotopicity generally refers to the monotonic CF differencecortical distance function. Sites in AI of naive rats had increasingly different CFs as distance between the sites increased (Fig. $4 B$; error bars are smaller than the markers). Noise-NB pairing significantly reduced average CF difference at long distances, whereas tone-NB pairing increased average CF difference (Kruskal-Wallis test for all three groups at each of the bins with distance $>1.4 \mathrm{~mm}, p<0.05$; post hoc Bonferroni's comparison, noise-NB vs naive, $p<0.05$; tone-NB vs naive $p<0.05)$. The CF difference was not different for the three groups at shorter distances, although many nearby sites in noise-NB paired animals had very different CFs. This is because the noise-NB paired animals often had large AI areas with similar CFs (thus small CF differences). If only the largest $20 \%$ of CF differences were compared, they were significantly larger in the noise-NB paired animals than in naive or tone-NB paired animals (noise-NB, $1.44 \pm$ 0.01 octaves; tone-NB, $1.19 \pm 0.01$ octaves; naive, $1.15 \pm 0.05$ octaves; Kruskal-Wallis test, $p<0.001$; post hoc Bonferroni's test, noise vs tone, $p<0.001$; noise vs naive, $p<0.0005$; tone vs naïve, $p>0.5)$.

In noise-NB paired animals, the percentage of RF overlap was greater at all distances analyzed (Fig. 4C; error bars are smaller than the markers), reflecting the broadened spectral tuning (Fig. $3 A$ ) and reduced CF difference. Tone-NB pairing reduced RF overlap to normal levels for distant sites $(1-1.6 \mathrm{~mm})$ but not for nearby sites. 
A

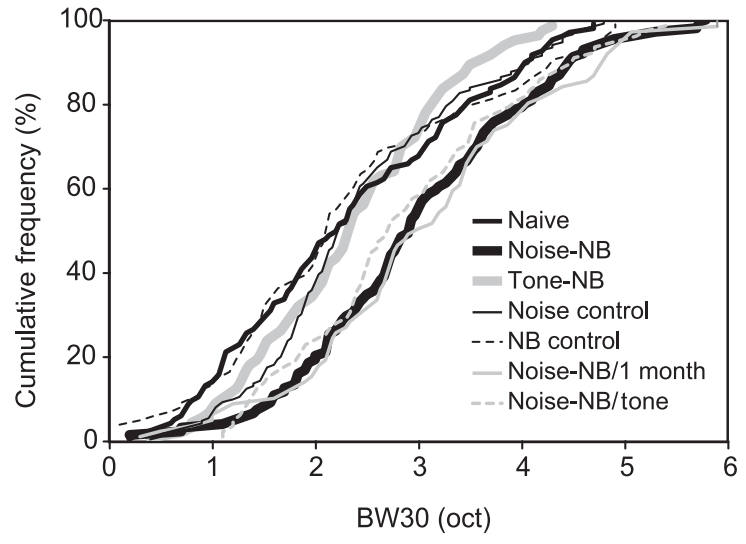

B

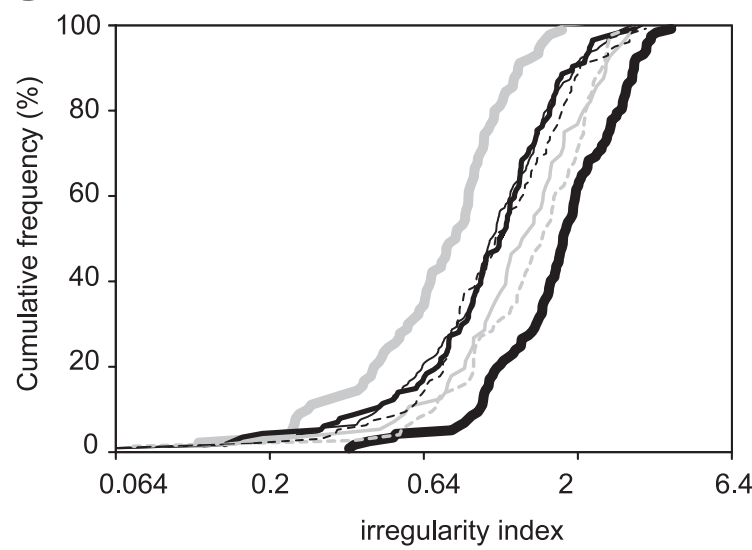

Figure 3. Quantitative degradation and refinement of the receptive fields of Al neurons. $A$, Noise-NB pairing broadened Al spectral tuning as indicated by increased response bandwidth at $30 \mathrm{~dB}$ above threshold. Subsequent pairing of NB stimulation with random tones (frequency of which was randomly chosen for each trial) sharpened the degraded spectral tuning. $B$, Noise-NB pairing significantly degraded Al receptive fields as measured with the RF irregularity index. Subsequent tone-NB pairing significantly improved RF. Noise experience (noise control) or NB stimulation (NB control) alone did not alter BW30 or RF irregularity index. The effects of noise-NB pairing were presented in animals examined 1 month after the last pairing procedure (noise-NB/1 month). One month of daily tone stimulation did not reverse noise-NB pairing effects.

\section{Reduced cortical discharge synchrony}

Cortical sensory neurons with similar receptive fields tend to discharge synchronously even in the absence of common sensory input, a phenomenon that is substantially mediated by intracortical horizontal connections (Engel et al., 1991). We analyzed synchrony between spontaneous spike trains simultaneously recorded from three to four sites in the auditory cortex. In tonotopically organized AI, the percentage of synchronous events decreases with increasing distance (Fig. 5) (ANCOVA with group as the variable, effect on distance as the covariant for all three groups; $\left.F_{(1,193)}=87.56 ; p<0.0001\right)$. Synchronization is generally higher between sites with larger RF overlap. Given the increased RF overlap in the noise-NB paired animals (Fig. 4C), we expected enhanced neuronal synchrony. Analysis indicated, however, that noise-NB pairing reduced the percentage of synchronous events (ANCOVA group effect, $F_{(2,193)}=31.85, p<$ 0.0001; post hoc Bonferroni's comparison, noise-NB vs naive, $p<$ $0.0001)$. Subsequent tone-NB pairing returned discharge synchrony to normal levels (tone-NB vs naive, $p>0.2$ ). The degree of synchrony, quantified using a $Z$-score (for details, see Materi-
A

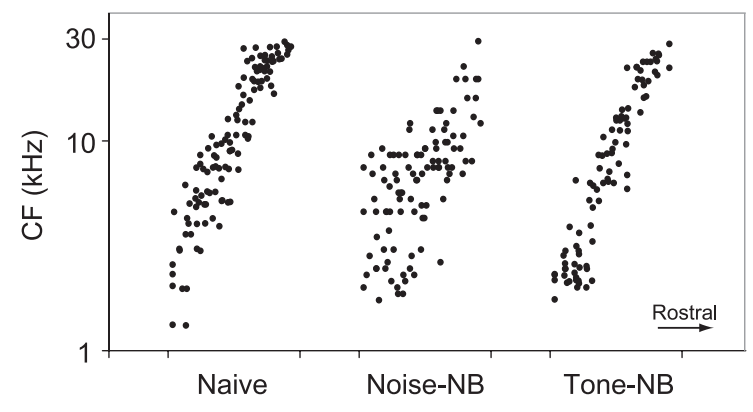

B

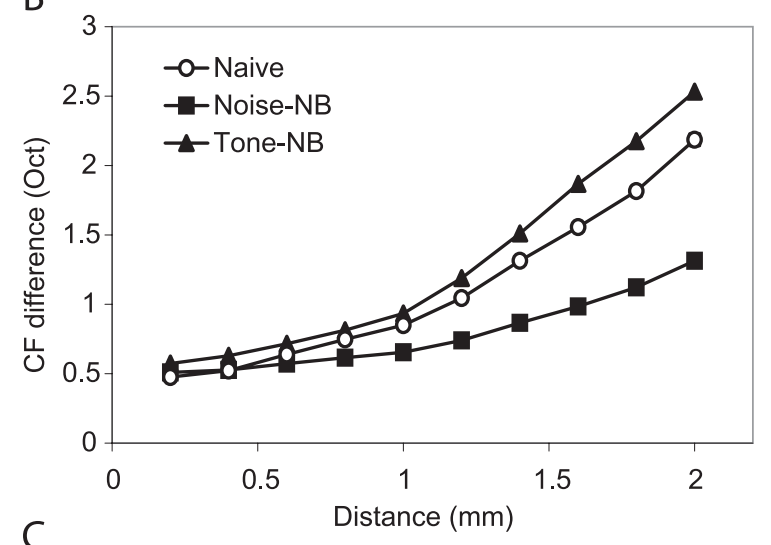

C

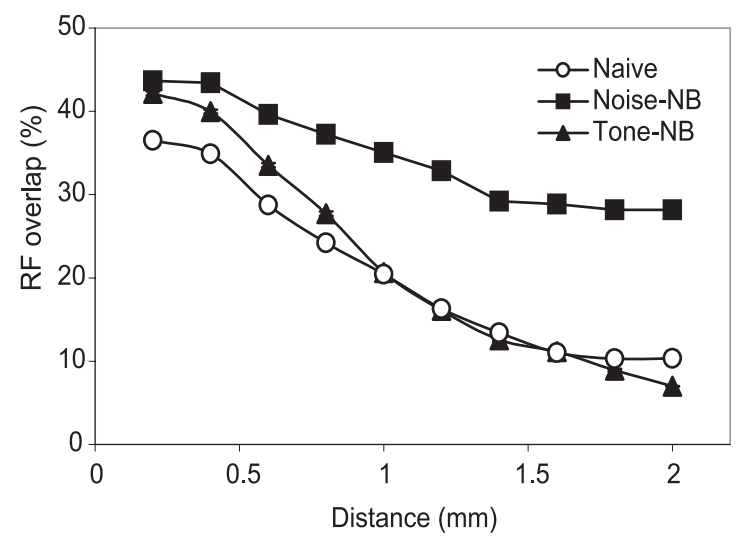

Figure 4. Quantitative degradation and refinement of the Al tonotopic maps. A, Rostralcaudal distribution of CFs along the AI tonotopic axis. $B$, Difference between CFs recorded from two sites as a function of the distance between the sites. C, Overlap of RFs of two sites as a function of the distance between the two sites. Note that noise-NB pairing disrupted Al tonotopicity, resulting in more scatted CF distribution, reduced CF difference at long distances, and increased RF overlap. Data from four noise-NB paired rats are shown in the graph for clarity. All six rats showed quantitatively similar effects. These degradation effects were reversed by subsequent tone-NB pairing.

als and Methods), was lower in noise-NB paired animals than in naive animals (ANCOVA, $F_{(2,193)}=42.55, p<0.0001$; Bonferroni's comparison, $p<0.0001)$ and was not different between tone-NB paired and naive animals ( $p>0.2$; data not shown). In the present studies, we analyzed only synchrony of spontaneous firing. Cortical neurons may exhibit different spatial patterns of neuronal synchrony when acoustically stimulated.

\section{Similarity between AI of noise-NB paired animals and} nonprimary auditory areas of naive animals

The degraded AI RFs in the noise-NB paired rats lost some of their distinctive characteristics (i.e., continuous response area, 


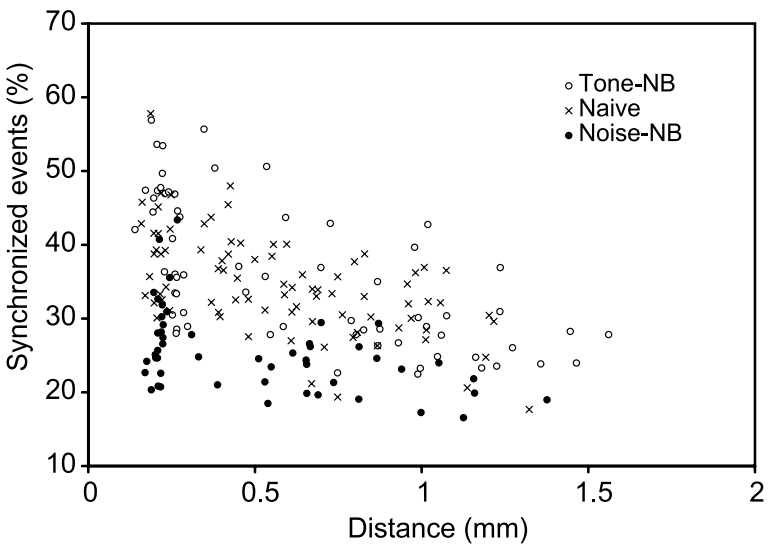

Figure 5. Percentage of synchronized spontaneous discharge as a function of distance. Noise-NB pairing reduced neuronal synchrony. Subsequent tone-NB pairing reversed the effect.

narrow tuning, and single-peaked tuning curve) and became similar to the RFs of nonprimary auditory neurons (Fig. 6A,B). We quantitatively compared characteristics of the AI neurons of the noise-NB paired animals with those of nonprimary auditory neurons of the noise-NB paired and naive animals. Only nonprimary auditory neurons responsive to some tonal stimuli (i.e., showing a peak in the poststimulus histogram) were included for these analyses (total area $1.42 \pm 0.37 \mathrm{~mm}^{2}$ for naive group, $1.66 \pm 0.44 \mathrm{~mm}^{2}$ for noise-NB group). The size of nonprimary auditory fields was relatively variable. Figure $6, A$ and $B$, shows two auditory cortical maps with large nonprimary auditory fields. Tuning bandwidth (as assessed with BW30) of the AI neurons in noise-NB paired animals was not different from that of nonprimary auditory neurons in naive animals (Kolmogorov-Smirnov test, $p>0.2$ ) (Fig. 7A). Similarly, noise-NB pairing increased RF irregularity of AI neurons to the level of nonprimary auditory neurons in naive rats (Kolmogorov-Smirnoff test, $p>0.1$ ) (Fig. $7 B)$. Discharge synchrony of AI neurons in the noise-NB paired animals was also similar to that of the nonprimary auditory neurons of naive animals (ANCOVA on percentage of synchronous

A naive

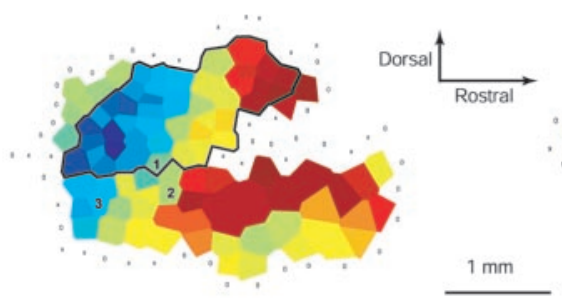

B noise-NB
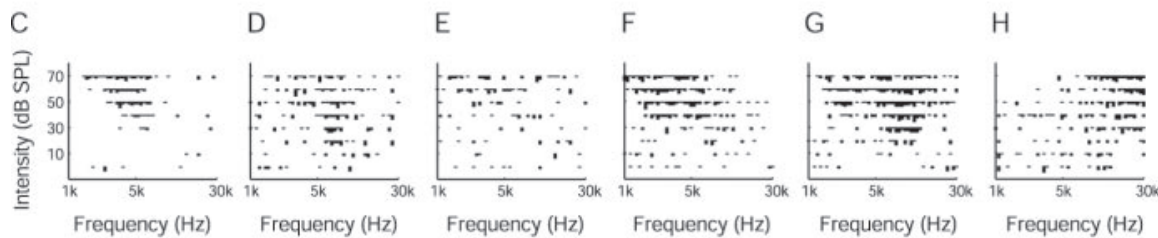

Figure 6. Similarity between the properties of degraded $\mathrm{Al}$ and naive nonprimary auditory neurons. $A, B$, Representative cortical maps recorded from naive and noise-NB animals, showing both Al and nonprimary auditory fields. Dark lines outline the primary auditory cortex in the maps ( 0 and $x$ indicate sites nonresponsive to pure tones). $(-H$, Receptive fields recorded from sites 1- 6 marked in $A$ and $B$. events, $F_{(2,150)}=0.15, p>0.5$ ) (Fig. 7C) (ANCOVA on $Z$-scores, $F_{(2,150)}=0.68, p>0.5$; data not shown). Thus, noise-NB pairing degraded functional organizations of the $\mathrm{AI}$ area into a state that was similar to that of nonprimary auditory fields.

We also compared nonprimary auditory fields in the noise-NB and the naive animals. Both BW30 and RF irregularity index were significantly higher for nonprimary auditory neurons in noise-NB paired animals than in naive animals (KolmogorovSmirnoff test, $p<0.05$ for both measures). Tone-NB pairing reversed these effects: BW30 was not different between naive and tone-NB paired animals (Fig. $7 A)(p>0.9999)$ and RF irregularity index was lower for tone-NB paired animals than for naive animals (Fig. $7 B)(p<0.02)$. Discharge synchrony of nonprimary auditory neurons was not different between the noise-NB animals and these controls (ANCOVA, $F_{(2,150)}=0.15, p>0.5$; $F_{(2,150)}=0.68 ; Z$-score, $p>0.5$; data not shown).

\section{Reduced discharge synchrony is correlated with RF irregularity}

Although noise-NB pairing reduced discharge synchrony between AI neurons, it did not alter the relationship between synchrony and distance (Fig. 5) (ANCOVA for group $\times$ distance interactions, $\left.F_{(2,150)}=0.048, p>0.5\right)$. Multiple-regression tests indicated that discharge synchrony is correlated with both distance (Fig. 5) $\left(r_{(156)}=-0.506 ; p<0.0001\right)$ and the product of the RF irregularity indices (Fig. 8) $\left(r_{(156)}=-0.442 ; p<0.0001\right)$ of the neurons, whereas the distance and the product of RF irregularity indices were not correlated $\left(r_{(156)}=-0.046, p>0.1\right.$; data not shown). Thus, the reduced synchrony in the noise-NB paired animals is likely related to degradation of their RFs.

\section{Discussion}

The degradation and subsequent refinement of the acoustic representations in adult primary auditory cortex observed in the present study reveals an underestimated and underappreciated capacity for cortical plasticity in adults. Sensory cortex is thought to be more plastic and malleable to reorganization by experience during an epoch of early development. Recent studies indicate that the adult cortex can also be reorganized, specifically when sensory input is attended to or reinforced (Merzenich et al., 1983; Diamond and Weinberger, 1986; Jenkins et al., 1990; Recanzone et al., 1992, 1993; Wang et al., 1995; Bakin et al., 1996; Nudo et al., 1996; Xerri et al., 1999; Plautz et al., 2000; Schoups et al., 2001; Zhang et al., 2001). The cholinergic and dopaminergic neuromodulator systems are thought to be involved in attention and reinforcement processes. Pairing stimulation of these neuromodulatory systems with sensory stimuli leads to large-scale cortical remodeling (Bakin and Weinberger, 1996; Kilgard and Merzenich, 1998a; Bao et al., 2001; Kisley and Gerstein, 2001). The current study demonstrates that this process is reversible.

It is generally accepted that the development of the cortical circuitry is instructed by both genetic processes and sensory inputs (Sur and Leamey, 2001; Katz and Crowley, 2002); however, the relative contributions of the intrinsic and en- 


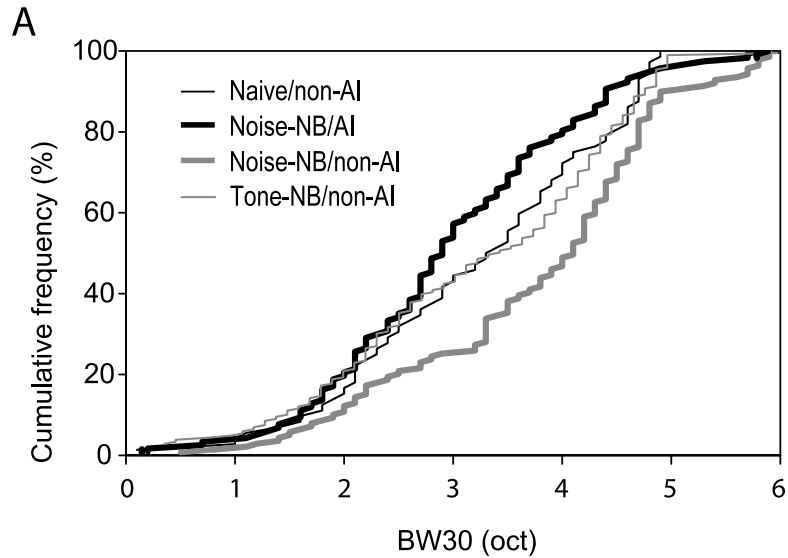

B
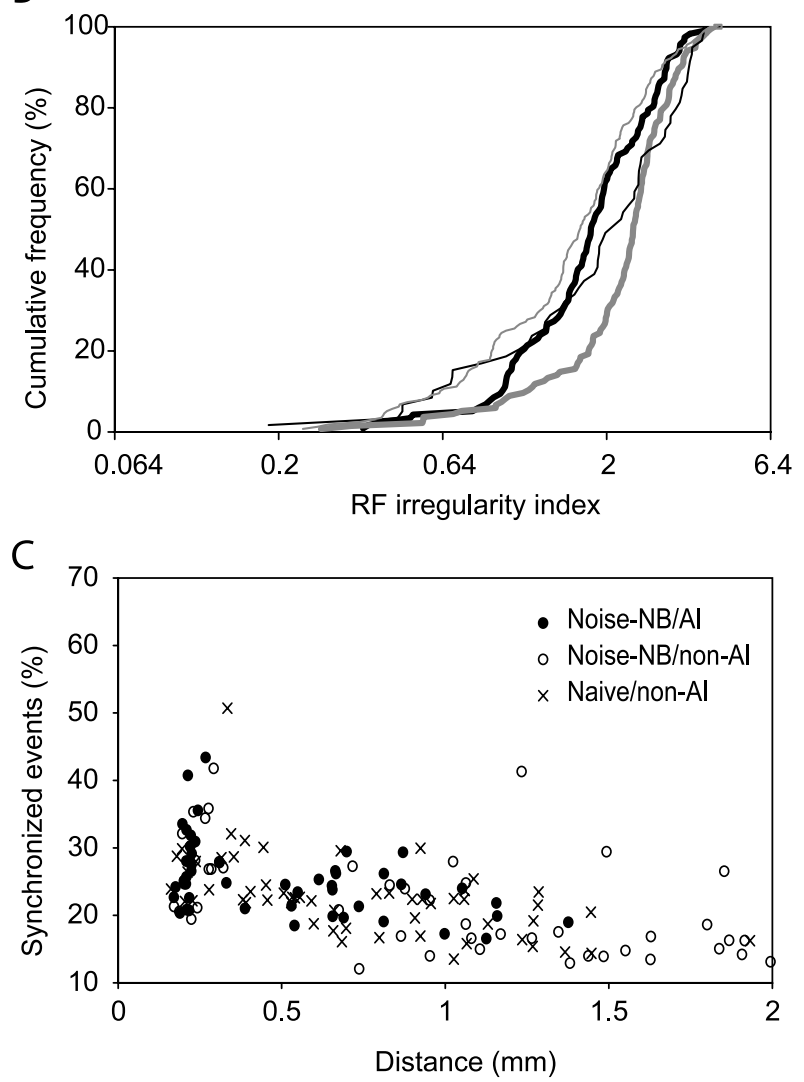

Figure 7. Similarity between properties of neurons in degraded $\mathrm{Al}$ and naive non-Al. $A$, Response bandwidth at $30 \mathrm{~dB}$ above threshold. $B$, A cumulative histogram of RF irregularity index. $C$, Percentage of synchronized spike events. Note that no significant differences were observed for these properties between the Al neurons of noise-NB paired animals and the nonprimary auditory neurons of naive animals.

vironmental influences to the functional architecture of the cortex are not entirely clear. In the present study, we were able to induce degradation of spectral tuning, tonotopicity, and functional connectivity in adult rat primary neurons, some of the most important features distinguishing AI neurons from nonprimary auditory neurons. These features are the likely results-substrates of sensory input-driven plasticity (Zhang et al., 2002; Chang and Merzenich, 2003). In contrast, the direction and size of the basic tonotopic axis (i.e., the orientation and distance between the low-CF and high-CF regions) remained unchanged. It remains to be determined whether these aspects of the AI circuit

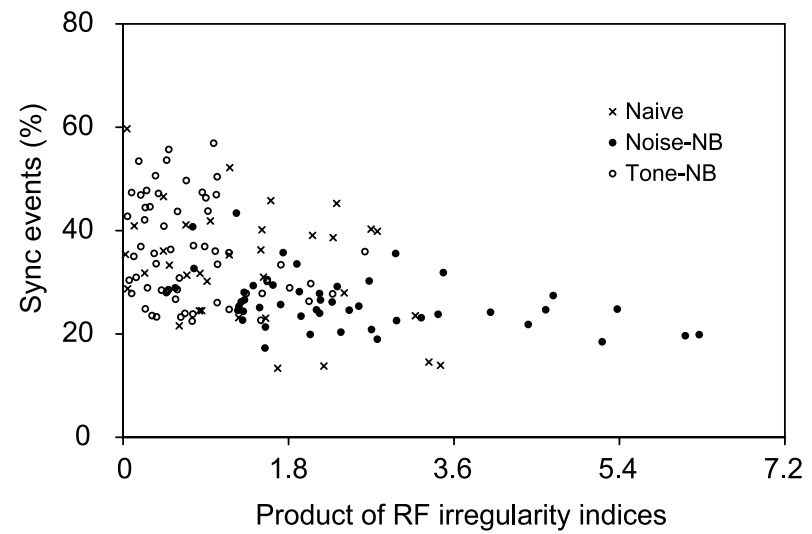

Figure 8. Neuronal synchrony as a function of RF irregularity index score. Neuronal synchrony decreased with increasing RF irregularity.

are genetically controlled or whether more fundamentally different stimuli are needed to alter them (Sharma et al., 2000).

Patterns of locally correlated activity, such as those resulting from wave-like spontaneous discharges or activated by patterned input, play an important role for the development of the normal functional organization of sensory cortex (Wiesel, 1982; Katz and Shatz, 1996; Sur and Leamey, 2001). Artificially altering the correlational structure of neural activity results in abnormal cortical circuitry. For example, globally synchronizing visual input by stimulating the optic nerve or strobe-rearing disrupts ocular dominance columns, orientation selectivity (Weliky and Katz, 1997), and directional selectivity of visual cortical neurons (Cynader and Chernenko, 1976; Humphrey and Saul, 1998). Synchronous auditory input (i.e., pulsed noise or clicks) disrupts the refinement of receptive fields and the development of tonotopic cortical map (Sanes and ConstantinePaton, 1985; Zhang et al., 2002). Decorrelation of binocular inputs by artificial squint leads to reduction in the number of binocular cortical neurons (Hubel and Wiesel, 1965; Lowel and Singer, 1992).

In adult cortex, temporally correlated inputs induce expansion of the somatosensory receptive fields (Clark et al., 1988; Recanzone et al., 1992; Wang et al., 1995). Our results indicate that pairing pulsed noise with NB stimulation broadens spectral tuning of adult AI neurons. The effects can be reversed by pairing tone pips with NB stimulation.

The reestablishment of tonotopicity with tone-NB pairing appears to depend on information provided by varying frequency tone stimulation. Results presented in Figure 1 indicated that more than half of AI could be activated synchronously by tone pips; however, this synchronization is relatively local compared with that induced by pulsed noise. With tone-pip stimulation, there are two populations of neurons, one activated, the other not activated. The population of activated neurons changes with the frequency of the tone pips. Although two neurons that are relatively far apart (e.g., $1 \mathrm{~mm}$ apart) may occasionally be synchronized, the probability of synchronization of their activity by varying-frequency tone pips is low. The probability of two neurons being synchronously activated by varying-frequency tone pips is, on average, a decreasing function of distance, which could provide critical information for refinement of the topographic representational maps. 
The effects of noise-NB pairing are qualitatively similar to those induced by noise rearing: broadly tuned, multipeaked receptive fields, disrupted tonotopicity, and reduced discharge correlation. The similarities between the noise-NB pairing and noise-rearing effects suggest that the principles that govern developmental plasticity and NB-enabled adult plasticity may be similar: locally correlated activity refines and globally synchronized activity degrades the functional organization of primary auditory cortex.

Pairing mild electrical stimulation of cholinergic or dopaminergic neurons with sensory stimulation of the cortex has been widely used to study mechanisms of cortical plasticity (Bakin and Weinberger, 1996; Kilgard and Merzenich, 1998a; Bao et al., 2001; Kisley and Gerstein, 2001; Verdier and Dykes, 2001; Ma and Suga, 2003). For these paradigms to be physiologically relevant, the neuromodulator system and auditory cortex should be activated as they are under physiological conditions. In the present study, NB was stimulated at $100 \mathrm{~Hz}$ for $200 \mathrm{msec}$ for each trial. NB neurons are capable of prolonged firing at such a rate under conditions of learning or sustained attention (Richardson and DeLong, 1990; Wilson and Rolls, 1990). The levels of NB electrical stimulation were set to desynchronize cortical EEG for only 1-2 sec, consistent with behaviorally induced cortical desynchronization. Thus, pairing of acoustic and NB stimulations mimics certain physiological conditions that normally occur in acoustic learning. Moreover, different forms of plasticity induced with sound-NB pairing share similarities with those that are behaviorally induced (Diamond and Weinberger, 1986, 1989; Recanzone et al., 1990, 1992, 1993; Bakin and Weinberger, 1996; Bakin et al., 1996; Kilgard et al., 2001). With these pairing paradigms, robust cortical plasticity can be induced conveniently and consistently in adult auditory cortex. We can also dissect distinctive roles of different neuromodulator systems in cortical plasticity (Bakin and Weinberger, 1996; Kilgard and Merzenich, 1998a,b; Bao et al., 2001, 2003; Kisley and Gerstein, 2001; Ma and Suga, 2003).

Basal forebrain neurons are activated by sustained attention in learning (Muir et al., 1993; Sarter et al., 2001; Arnold et al., 2002), conditions in which adult cortical plasticity often occurs. These neurons broadly innervate sensory cortices and are well suited to signal a learning context for cortical plasticity (Mesulam et al., 1983). Our results support the notion that basal forebrain cholinergic activity serves as a gating signal that allows the cortex to operate specifically on behaviorally important stimuli. The specific form of plasticity is determined by the properties of the coincidental sensory input (Dykes, 1997; Kilgard et al., 2001).

Repetitive pairing of noise with basal forebrain stimulation used in our study simulates a condition of sustained attention to synchronizing noise. Heavily attended, synchronous somatosensory stimulation to multiple fingers has been shown to disrupt sensory functions and cause focal hand dystonia (Byl et al., 1996; Elbert et al., 1998; Sterr et al., 1998a; Bara-Jimenez et al., 2000; Blake et al., 2002). The degraded cortical stimulus representations observed in the present and other studies may be an underlying mechanism for the impaired sensory and motor functions (Byl et al., 1996, 2000; Elbert et al., 1998; Sterr et al., 1998b; Blake et al., 2002). Redifferentiation of degraded cortical representations through plasticity induced with asynchronous sensory stimulation may be a plausible method to restore function (Byl and McKenzie, 2000; Zeuner et al., 2002).

\section{References}

Ahissar E, Vaadia E, Ahissar M, Bergman H, Arieli A, Abeles M (1992) Dependence of cortical plasticity on correlated activity of single neurons and on behavioral context. Science 257:1412-1415.

Arnold HM, Burk JA, Hodgson EM, Sarter M, Bruno JP (2002) Differential cortical acetylcholine release in rats performing a sustained attention task versus behavioral control tasks that do not explicitly tax attention. Neuroscience 114:451-460.

Bakin JS, Weinberger NM (1996) Induction of a physiological memory in the cerebral cortex by stimulation of the nucleus basalis. Proc Natl Acad Sci USA 93:11219-11224.

Bakin JS, South DA, Weinberger NM (1996) Induction of receptive field plasticity in the auditory cortex of the guinea pig during instrumental avoidance conditioning. Behav Neurosci 110:905-913.

Bao S, Chan VT, Merzenich MM (2001) Cortical remodeling induced by activity of ventral tegmental dopamine neurons. Nature 412:79-83.

Bao S, Chan VT, Zhang LI, Merzenich MM (2003) Suppression of cortical representation through backward conditioning. Proc Natl Acad Sci USA 100:1405-1408.

Bara-Jimenez W, Shelton P, Sanger TD, Hallett M (2000) Sensory discrimination capabilities in patients with focal hand dystonia. Ann Neurol 47:377-380.

Blake DT, Byl NN, Cheung S, Bedenbaugh P, Nagarajan S, Lamb M, Merzenich M (2002) Sensory representation abnormalities that parallel focal hand dystonia in a primate model. Somatosens Mot Res 19:347-357.

Byl N, Wilson F, Merzenich M, Melnick M, Scott P, Oakes A, McKenzie A (1996) Sensory dysfunction associated with repetitive strain injuries of tendonitis and focal hand dystonia: a comparative study. J Orthop Sports Phys Ther 23:234-244.

Byl NN, McKenzie A (2000) Treatment effectiveness for patients with a history of repetitive hand use and focal hand dystonia: a planned, prospective follow-up study. J Hand Ther 13:289-301.

Byl NN, McKenzie A, Nagarajan SS (2000) Differences in somatosensory hand organization in a healthy flutist and a flutist with focal hand dystonia: a case report. J Hand Ther 13:302-309.

Chang EF, Merzenich MM (2003) Environmental noise retards auditory cortical development. Science 300:498-502.

Clark SA, Allard T, Jenkins WM, Merzenich MM (1988) Receptive fields in the body-surface map in adult cortex defined by temporally correlated inputs. Nature 332:444-445.

Cynader M, Chernenko G (1976) Abolition of direction selectivity in the visual cortex of the cat. Science 193:504-505.

Diamond DM, Weinberger NM (1986) Classical conditioning rapidly induces specific changes in frequency receptive fields of single neurons in secondary and ventral ectosylvian auditory cortical fields. Brain Res 372:357-360.

Diamond DM, Weinberger NM (1989) Role of context in the expression of learning-induced plasticity of single neurons in auditory cortex. Behav Neurosci 103:471-494.

Dykes RW (1997) Mechanisms controlling neuronal plasticity in somatosensory cortex. Can J Physiol Pharmacol 75:535-545.

Eggermont JJ (1992) Neural interaction in cat primary auditory cortex. Dependence on recording depth, electrode separation, and age. J Neurophysiol 68:1216-1228.

Eggermont JJ (1994) Neural interaction in cat primary auditory cortex II. Effects of sound stimulation. J Neurophysiol 71:246-270.

Elbert T, Candia V, Altenmuller E, Rau H, Sterr A, Rockstroh B, Pantev C, Taub E (1998) Alteration of digital representations in somatosensory cortex in focal hand dystonia. NeuroReport 9:3571-3575.

Engel AK, Konig P, Kreiter AK, Singer W (1991) Interhemispheric synchronization of oscillatory neuronal responses in cat visual cortex. Science 252:1177-1179.

Feldman DE (2000) Timing-based LTP and LTD at vertical inputs to layer II/III pyramidal cells in rat barrel cortex. Neuron 27:45-56.

Froemke RC, Dan Y (2002) Spike-timing-dependent synaptic modification induced by natural spike trains. Nature 416:433-438.

Hollerman JR, Schultz W (1998) Dopamine neurons report an error in the temporal prediction of reward during learning. Nat Neurosci 1:304-309.

Hubel DH, Wiesel TN (1965) Binocular interaction in striate cortex of kittens reared with artificial squint. J Neurophysiol 28:1041-1059.

Humphrey AL, Saul AB (1998) Strobe rearing reduces direction selectivity 
in area 17 by altering spatiotemporal receptive-field structure. J Neurophysiol 80:2991-3004.

Jenkins WM, Merzenich MM, Ochs MT, Allard T, Guic-Robles E (1990) Functional reorganization of primary somatosensory cortex in adult owl monkeys after behaviorally controlled tactile stimulation. J Neurophysiol 63:82-104.

Ji W, Gao E, Suga N (2001) Effects of acetylcholine and atropine on plasticity of central auditory neurons caused by conditioning in bats. J Neurophysiol 86:211-225.

Juliano SL, Ma W, Eslin D (1991) Cholinergic depletion prevents expansion of topographic maps in somatosensory cortex. Proc Natl Acad Sci USA 88:780-784.

Katz LC, Crowley JC (2002) Development of cortical circuits: lessons from ocular dominance columns. Nat Rev Neurosci 3:34-42.

Katz LC, Shatz CJ (1996) Synaptic activity and the construction of cortical circuits. Science 274:1133-1138.

Kilgard MP, Merzenich MM (1998a) Cortical map reorganization enabled by nucleus basalis activity. Science 279:1714-1718.

Kilgard MP, Merzenich MM (1998b) Plasticity of temporal information processing in the primary auditory cortex. Nat Neurosci 1:727-731.

Kilgard MP, Pandya PK, Vazquez J, Gehi A, Schreiner CE, Merzenich MM (2001) Sensory input directs spatial and temporal plasticity in primary auditory cortex. J Neurophysiol 86:326-338.

Kisley MA, Gerstein GL (2001) Daily variation and appetitive conditioninginduced plasticity of auditory cortex receptive fields. Eur J Neurosci 13:1993-2003.

Levene H (1960) Robust tests for equality of variances. In: Contributions to probability and statistics: essays in honor of Harold Hotelling (Olkin I, ed), pp 278-292. Stanford, CA: Stanford UP.

Lowel S, Singer W (1992) Selection of intrinsic horizontal connections in the visual cortex by correlated neuronal activity. Science 255:209-212.

Ma X, Suga N (2003) Augmentation of plasticity of the central auditory system by the basal forebrain and/or somatosensory cortex. J Neurophysiol 89:90-103.

Maalouf M, Miasnikov AA, Dykes RW (1998) Blockade of cholinergic receptors in rat barrel cortex prevents long-term changes in the evoked potential during sensory preconditioning. J Neurophysiol 80:529-545.

Markram H, Lubke J, Frotscher M, Sakmann B (1997) Regulation of synaptic efficacy by coincidence of postsynaptic APs and EPSPs. Science 275:213-215.

Mercado E, Bao S, Orduna I, Gluck MA, Merzenich MM (2001) Basal forebrain stimulation changes cortical sensitivities to complex sound. NeuroReport 12:2283-2287.

Merzenich MM, Kaas JH, Wall J, Nelson RJ, Sur M, Felleman D (1983) Topographic reorganization of somatosensory cortical areas $3 \mathrm{~b}$ and 1 in adult monkeys following restricted deafferentation. Neuroscience $8: 33-55$.

Merzenich MM, Recanzone GH, Jenkins WM, Grajski KA (1990) Adaptive mechanisms in cortical networks underlying cortical contributions to learning and nondeclarative memory. Cold Spring Harb Symp Quant Biol 55:873-887.

Mesulam MM, Mufson EJ, Wainer BH, Levey AI (1983) Central cholinergic pathways in the rat: an overview based on an alternative nomenclature (Ch1-Ch6). Neuroscience 10:1185-1201.

Metherate R, Weinberger NM (1990) Cholinergic modulation of responses to single tones produces tone-specific receptive field alterations in cat auditory cortex. Synapse 6:133-145.

Metherate R, Ashe JH (1993) Nucleus basalis stimulation facilitates thalamocortical synaptic transmission in the rat auditory cortex. Synapse $14: 132-143$.

Metherate R, Tremblay N, Dykes RW (1988) The effects of acetylcholine on response properties of cat somatosensory cortical neurons. J Neurophysiol 59:1231-1252.

Muir JL, Page KJ, Sirinathsinghji DJ, Robbins TW, Everitt BJ (1993) Excitotoxic lesions of basal forebrain cholinergic neurons: effects on learning, memory and attention. Behav Brain Res 57:123-131.

Nudo RJ, Milliken GW, Jenkins WM, Merzenich MM (1996) Usedependent alterations of movement representations in primary motor cortex of adult squirrel monkeys. J Neurosci 16:785-807.
Perkel DH, Gerstein GL, Moore GP (1967) Neuronal spike trains and stochastic point processes. II. Simultaneous spike trains. Biophys J 7:419-440.

Plautz EJ, Milliken GW, Nudo RJ (2000) Effects of repetitive motor training on movement representations in adult squirrel monkeys: role of use versus learning. Neurobiol Learn Mem 74:27-55.

Quinn GP, Keough MJ (2002) Experimental design and data analysis for biologist. Cambridge, UK: Cambridge UP.

Recanzone GH, Allard TT, Jenkins WM, Merzenich MM (1990) Receptivefield changes induced by peripheral nerve stimulation in SI of adult cats. J Neurophysiol 63:1213-1225.

Recanzone GH, Merzenich MM, Jenkins WM, Grajski KA, Dinse HR (1992) Topographic reorganization of the hand representation in cortical area $3 \mathrm{~b}$ owl monkeys trained in a frequency-discrimination task. J Neurophysiol 67:1031-1056.

Recanzone GH, Schreiner CE, Merzenich MM (1993) Plasticity in the frequency representation of primary auditory cortex following discrimination training in adult owl monkeys. J Neurosci 13:87-103.

Richardson RT, DeLong MR (1990) Context-dependent responses of primate nucleus basalis neurons in a go/no-go task. J Neurosci $10: 2528-2540$

Sanes DH, Constantine-Paton M (1985) The sharpening of frequency tuning curves requires patterned activity during development in the mouse, Mus musculus. J Neurosci 5:1152-1166.

Sarter M, Givens B, Bruno JP (2001) The cognitive neuroscience of sustained attention: where top-down meets bottom-up. Brain Res Brain Res Rev 35:146-160.

Schoups A, Vogels R, Qian N, Orban G (2001) Practising orientation identification improves orientation coding in V1 neurons. Nature 412:549-553.

Schultz W, Dickinson A (2000) Neuronal coding of prediction errors. Annu Rev Neurosci 23:473-500.

Sengpiel F, Stawinski P, Bonhoeffer T (1999) Influence of experience on orientation maps in cat visual cortex. Nat Neurosci 2:727-732.

Sharma J, Angelucci A, Sur M (2000) Induction of visual orientation modules in auditory cortex. Nature 404:841-847.

Shulz DE, Sosnik R, Ego V, Haidarliu S, Ahissar E (2000) A neuronal analogue of state-dependent learning. Nature 403:549-553.

Simons DJ, Land PW (1987) Early experience of tactile stimulation influences organization of somatic sensory cortex. Nature 326:694-697.

Stark H, Scheich H (1997) Dopaminergic and serotonergic neurotransmission systems are differentially involved in auditory cortex learning: a long-term microdialysis study of metabolites. J Neurochem 68:691-697.

Sterr A, Muller MM, Elbert T, Rockstroh B, Pantev C, Taub E (1998a) Changed perceptions in Braille readers. Nature 391:134-135.

Sterr A, Muller MM, Elbert T, Rockstroh B, Pantev C, Taub E (1998b) Perceptual correlates of changes in cortical representation of fingers in blind multifinger Braille readers. J Neurosci 18:4417-4423.

Sur M, Leamey CA (2001) Development and plasticity of cortical areas and networks. Nat Rev Neurosci 2:251-262.

Tremblay N, Warren RA, Dykes RW (1990) Electrophysiological studies of acetylcholine and the role of the basal forebrain in the somatosensory cortex of the cat. II. Cortical neurons excited by somatic stimuli. J Neurophysiol 64:1212-1222.

Verdier D, Dykes RW (2001) Long-term cholinergic enhancement of evoked potentials in rat hindlimb somatosensory cortex displays characteristics of long-term potentiation. Exp Brain Res 137:71-82.

Wang X, Merzenich MM, Sameshima K, Jenkins WM (1995) Remodelling of hand representation in adult cortex determined by timing of tactile stimulation. Nature 378:71-75.

Webster HH, Hanisch UK, Dykes RW, Biesold D (1991a) Basal forebrain lesions with or without reserpine injection inhibit cortical reorganization in rat hindpaw primary somatosensory cortex following sciatic nerve section. Somatosens Mot Res 8:327-346.

Webster HH, Rasmusson DD, Dykes RW, Schliebs R, Schober W, Bruckner G, Biesold D (1991b) Long-term enhancement of evoked potentials in raccoon somatosensory cortex following coactivation of the nucleus basalis of Meynert complex and cutaneous receptors. Brain Res 545:292-296. 
Weliky M, Katz LC (1997) Disruption of orientation tuning in visual cortex by artificially correlated neuronal activity. Nature 386:680-685.

Wiesel TN (1982) Postnatal development of the visual cortex and the influence of environment. Nature 299:583-591.

Wiesel TN, Hubel DH (1965) Comparison of the effects of unilateral and bilateral eye closure on cortical unit responses in kittens. J Neurophysiol 28:1029-1040.

Wilson FA, Rolls ET (1990) Learning and memory are reflected in the responses of reinforcement-related neurons in the primate basal forebrain. J Neurosci 10:1254-1267.

Xerri C, Merzenich MM, Jenkins W, Santucci S (1999) Representational plasticity in cortical area $3 \mathrm{~b}$ paralleling tactual-motor skill acquisition in adult monkeys. Cereb Cortex 9:264-276.
Zeuner KE, Bara-Jimenez W, Noguchi PS, Goldstein SR, Dambrosia JM, Hallett M (2002) Sensory training for patients with focal hand dystonia. Ann Neurol 51:593-598.

Zhang LI, Tao HW, Holt CE, Harris WA, Poo M (1998) A critical window for cooperation and competition among developing retinotectal synapses. Nature 395:37-44.

Zhang LI, Bao S, Merzenich MM (2001) Persistent and specific influences of early acoustic environments on primary auditory cortex. Nat Neurosci 4:1123-1130.

Zhang LI, Bao S, Merzenich MM (2002) Disruption of primary auditory cortex by synchronous auditory inputs during a critical period. Proc Natl Acad Sci USA 99:2309-2314. 